\title{
Uma análise do programa luz para todos do Governo Federal
}

\section{An analysis of the light for all program of the Federal \\ Government}

\section{Gilmar Fialho de Freitas}

gilmarffreitas@yahoo.com.br

Graduado em Geografia pela Universidade Federal de Viçosa (UFV) e mestre em

Extensão Rural pela mesma instituição

\section{Marcelo Leles Romarco de Oliveira}

marcelo.romarco@ufv.br

Doutor em Ciências Sociais em Desenvolvimento, Agricultura e Sociedade pela

Universidade Federal Rural do Rio de Janeiro (UFRRJ). Professor do Departamento de Economia Rural na Universidade Federal de Viçosa (UFV)

Recebido em: 26/10/2017

Aprovado em: 16/11/2017
Revista do Programa de Pós-Graduação em Extensão Rural (UFV) 


\title{
RESUMO
}

Este artigo procura fazer um debate em torno da criação do programa do governo Federal Luz para Todos", criado em novembro de 2003 pelo governo do presidente Luiz Inácio Lula da Silva O objetivo era levar energia elétrica a dois milhões de lares brasileiros que, à época, permaneciam sem acesso a uma fonte confiável e permanente de eletricidade. Até janeiro de 2016, o programa já tinha atendido cerca de 15,6 milhões de moradores das diversas regiões brasileiras, muitos desses morando em assentamentos rurais, reservas extrativistas, áreas quilombolas e terras indígenas. Na proposta analisada é possível perceber que as dimensões do Programa Luz para Todos, não parece ficar dúvidas quanto à sua importância como política pública de inclusão social. Entretanto, a grande maioria das políticas públicas apresentadas no Brasil tem destacado mais o processo de formulação e elaboração de programas e projetos, ao passo que negligencia outras etapas que não podem ser consideradas irrelevantes ao ciclo da política, como o acompanhamento e a avaliação dos processos, dos resultados e impactos gerados por essas políticas.

Palavras-chave: Políticas Públicas; Estado; Agricultura Familiar; Luz para Todos.

\begin{abstract}
This paper aims to do a debate about the creation of the Federal Government "Light for all" created in November 2003 by the government of President Lula, whose goal was to bring electricity to two million Brazilian homes that, at the time, remained without access to permanent and reliable source of electricity. By January 2016, the program had already served nearly 15.6 million residents of several Brazilian regions, many of those living in rural settlements, extractive reserves, quilombo areas and indigenous lands. In the proposal analyzed is possible to realize that the dimensions of the program Light for all seems to be no doubt as to its importance as a public policy of social inclusion. However, the vast majority of public policies in Brazil has shown outstanding plus the process of formulation and preparation of programs and projects, while neglecting other steps that cannot be considered irrelevant to the policy cycle, such as monitoring and evaluation processes, the results and impacts of these policies.
\end{abstract}

Keywords: Public Policy, State and Energy. 


\section{Introdução}

O presente trabalho tem por objetivo apresentar, de forma breve e sistematizada um debate em torno da criação do programa do governo federal "Luz para Todos", criado em novembro de 2003 pelo governo do presidente Luiz Inácio Lula da Silva. O programa visava levar energia elétrica a dois milhões de lares brasileiros que, à época, permaneciam sem acesso a uma fonte confiável e permanente de eletricidade. Essa realidade se estendia, principalmente, na zona rural brasileira e nas regiões mais distantes do país, onde é possível encontrar uma gama de atores que podemos classificá-los como agricultores familiares $^{1}$ e que a partir de 2003 passaram fazer parte com mais incisão da pauta de programas e políticas governamentais.

A meta inicial foi atingida em maio de 2009, o que representou tirar da escuridão cerca de 10 milhões de pessoas que vivem em áreas rurais e predominantemente pobres. Até novembro de 2016 o programa já havia atendido cerca de 15,9 milhões de moradores das áreas rurais brasileira, principalmente, em assentamentos rurais, reservas extrativistas, terras indígenas, territórios quilombolas e áreas com forte presença de agricultores familiares. $\mathrm{O}$ alcance do programa foi considerado positivo e estimulou o governo federal a prorroga-lo até dezembro de 2018. A extensão desse prazo ocorreu por Decreto presidencial de $\mathrm{N}^{\mathrm{o}}$ 8.387, de 30 de dezembro de 2014 (MME, 2017).

Para criação do programa o governo utilizou como referência o Censo Demográfico realizado no ano de 2000 pelo Instituto Brasileiro de Geografia e Estatística (IBGE). O mapeamento indicou que muitas áreas no país sem energia elétrica estavam associadas a um grupo de pessoas que viviam em condições precárias. Para confirmar a questão, observou-se que o Índice de Desenvolvimento Humano (IDH) das regiões que seriam alvo do programa "Luz para Todos" também eram inferiores à média nacional.

\footnotetext{
${ }^{1}$ Neste trabalho entendemos que o agricultor familiar é aquele ator social que tem uma forma de produção que predomina a integração entre gestão e trabalho, relações sociais e culturais. Nesse tipo de agricultura são os agricultores familiares que dirigem o processo produtivo, dando ênfase à diversificação e utilizando o trabalho familiar, eventualmente complementado pelo trabalho assalariado. Em 2006, o governo federal promulgou a Lei 11.326, de 24 de julho de 2006, que estabelece as diretrizes para a formulação da Política Nacional da Agricultura Familiar e Empreendimentos Familiares Rurais. Nesse contexto podemos encontrar os seguintes atores: agricultores familiares tradicionais; assentados da reforma agrária; pescadores artesanais; quilombolas; indígenas; seringueiros; ribeirinhos; extrativistas; grupos sociais atingidos por barragens e grupos assemelhados.
} 
Conforme analisa Carnoy (1988), as teorias do Estado liberal associam-se a uma visão pluralista de que o governo deve estar a serviço do povo, ou seja, que esteja de acordo com as necessidades da maioria, assim como é apresentado no programa "Luz para Todos". A partir de então, coube ao Estado desprender-se dos antigos atos de coerção e repressão anteriores ao renascimento, e renovar-se através de mecanismos de controles. É exatamente sobre estas bases que se desenvolve a teoria do Estado liberal, que se baseia em liberdades individuais e a busca pelo bem comum nas suas ações.

Nesse contexto, o caso do programa "Luz para Todos", que permite acesso à luz elétrica, principalmente para os mais pobres, passa pela necessidade do Estado de promover o desenvolvimento do país, e situa-se a população que nesse caso específico também se sente beneficiada pelas iniciativas do programa. As transformações que podem ser relacionadas à implantação do programa dizem respeito, principalmente, à inserção de padrões de vida antes apenas urbano no meio rural brasileiro, já que a presença da energia elétrica é capaz de alterar toda uma dinâmica de vida dessas populações.

Além dessa introdução o artigo está estruturado em quatro partes. A primeira traz alguns elementos metodológicos que permitiram elaborar o caminho para as reflexões contidas nesse trabalho. Na segunda analisa-se alguns elementos que permitem compreender o papel do Estado na formulação e mediação dessa política. Na terceira, discorrermos sobre algumas abordagens sobre o que tratamos de política pública, para uma melhor compreensão sobre o programa "Luz para Todos" do governo federal. Por fim, a título de considerações finais, são retomadas algumas questões que foram debatidas ao longo do trabalho.

\section{Metodologia}

Neste trabalho, a elaboração das discussões apresentadas baseia-se em documentos (leis, relatórios, decretos e portarias) que têm um papel-chave. Entretanto, o documento deve ser considerado como um dos possíveis instrumentos de pesquisa, uma vez que, de antemão, acredita-se, na impossibilidade da existência de algum documentoverdade. Conforme analisa Melucci (2005), o maior problema a ser destacado é que a prática de tratamento desse tipo de textos, na pesquisa social, é, geralmente, ingênua, uma vez que muitos cientistas ignoram e/ou não consideram o fato de que os textos referentes a sujeitos coletivos são sempre produções organizativas. Nesse sentido, um documento é 
sempre no resultado de uma dinâmica institucional e, por isso mesmo, são sempre construções dialógicas e controvertidas. Nas palavras do autor (ibid.),

[...] documentos ou textos definidos, de qualquer maneira, nos colocam em contato com representações e percepções tornadas mais permanentes em qualquer forma institucional. Um documento escrito, um livro, um manifesto, um registro de processo ou ata de assembleia, contêm uma representação que era percebida ativa e relacionalmente no momento em que foi produzida (p.324).

Nessa perspectiva, a discussão apresentada traz como ponto principal o estudo das obras de alguns autores que tratam da temática das políticas públicas. Os textos, artigos e documentos pesquisados têm a finalidade de referenciar as escolhas e mesmo contribuir para que a análise proposta seja subsidiada por pensamentos relevantes no interior do campo cientifico.

Para além das pesquisas bibliográficas outra fonte de levantamento das informações que vão compor esse trabalho, foi a coleta de dados sobre o programa "Luz para Todos" em banco de dados elaborados pelo Ministério das Minas e Energia (MME), que permitiram traçar uma evolução dos resultados alcançados pelo programa. Portanto, este trabalho foi elaborado exclusivamente através de estudos bibliográficos e documentais pertinentes ao tema desenvolvido.

\section{O papel do Estado e o Luz para Todos}

O Estado brasileiro ao criar um programa de universalização e acesso de energia elétrica, principalmente, para os remotos cantos do país, nos remete as reflexões elaboradas por Giddens (2001) que permitem entender, esse tipo de ação como "mediação institucional de poder", ou seja, as ações são coordenadas por instituições que são a maior expressão dessas relações de poder. Nesse ponto destaca-se a atuação do programa através de uma gestão participativa, em que todos os órgãos interessados (ministérios, governos estaduais, distribuidoras de energia e comunidades) interagem na execução do programa. “Todos os tipos de domínio, portanto, residem na mediação institucional do poder, mas são canalizados pelo uso de estratégias definidas de controle, que naturalmente dependem, em grau significativo, da forma de dominação de onde são geradas" (GIDDENS, 2001, p. 36).

Giddens (2001) também corrobora para entender que a capacidade de atuação do Estado em determinadas circunstâncias e cenários demonstra a capacidade de alterá-los 
segundo sua necessidade. Nesse ponto de vista entra as discussões sobre "poder", que são apresentadas pelo autor, dotados de sua capacidade transformadora. Essa relação de poder é expressa no fato da capacidade de decisão dos agentes, mesmo que essas decisões gerem controvérsias, já que estas são relações típicas da forma de dominação.

Para Bourdieu (1996) a presença do Estado se dá como resultado de um processo de concentração do capital de força física, econômica, simbólica e cultural, no qual permite ao Estado exercer o poder. Segundo essa afirmação, a construção de um Estado, segundo as ideias desse autor, passa pela necessidade de construção de um campo de poder. É principalmente sobre o poder simbólico que se situa a fonte de todo o domínio do Estado na perspectiva de Bourdieu, já que “[...] as administrações públicas e seus representantes são grandes produtores de problemas sociais que a ciência social frequentemente apenas ratifica, retomando-os por sua conta como problemas sociológicos [...]" (BOURDIEU, 1996, p. 95).

Num outro momento, Bourdieu (1996) faz referência à associação entre desenvolvimento progressivo do reconhecimento da legitimidade dos impostos oficiais à emergência de certa forma de nacionalismo, em que se subentende a formação de um território de uma realidade particular e que assuma as mesmas obrigações. No programa "Luz para Todos” observa-se uma hipótese de acesso dos beneficiários ao serviço público em questão, muitas vezes em detrimento de que os cidadãos pagam seus impostos e por isso devem desfrutar de alguns serviços que são de seu direito, como no caso a luz elétrica. Através da noção de território observa-se que o Estado busca uma unificação, tanto de suas bases físicas quanto mentais, à medida que cria no cidadão a ideia de pertencimento, que geralmente é regida por direitos e deveres.

Outro aspecto fundamental na obra de Bourdieu (1996) trata da questão da universalização, que é fundamental a compreensão de seu universo burocrático, o que facilita o entendimento da gênese e estrutura do universo de agentes que compõem o Estado. O caráter universal do Estado confere a este uma valorização do coletivo em contraposição aos interesses individuais, e esse reconhecimento se torna legítimo.

Na questão do programa "Luz para Todos", conforme aponta o Ministério de Minas e Energia, este conta com uma Comissão Nacional de Universalização (CNU), coordenada pelo Ministério de Minas e Energia e integrado pela Casa Civil e pelo Ministérios de Desenvolvimento Agrário; Agricultura, Pecuária e Abastecimento; Desenvolvimento Social e Combate à Fome; Integração Nacional; Educação; Saúde; 
Meio Ambiente; Ciência e Tecnologia; Indústria do Desenvolvimento e Comércio Exterior e também pelo Banco Nacional de Desenvolvimento Econômico e Social (BNDES); Agência Nacional de Energia Elétrica (ANEEL) e o Fórum de Secretários de Energia. O CNU estabelece ações interministeriais para o desenvolvimento das comunidades rurais. A estrutura executiva do Programa é composta pelo Comitê Gestor Nacional (CGN) e pelos Comitês Gestores Estaduais (CGEs).

Já na perspectiva de Foucault (2006), o exercício do poder que tem o governo se dá através da ação do Estado sobre a ação da população. Portanto, o ato de governar significa estruturar o campo de ação dos outros, principalmente através de relações institucionalizadas. Nessa perspectiva de análise a relação de poder acontece na ação de uns sobre os outros ao longo de suas interações no espaço. Portanto, a questão da governabilidade aparece como formas de racionalidade, de procedimentos técnicos, formas de instrumentalização que permitem aos agentes do Estado exercer o poder sobre a ação dos outros.

Nos estudos elaborados por Foucault (2006) destaca-se a concepção de governo de La Perrière, em que o governo aparece como uma forma ordenada de disposição das coisas a fim de que seu objetivo seja adequado a cada coisa a governar. O Estado brasileiro apresenta diversas finalidades e ações que remetem a seus interesses e que de alguma maneira atingem a população e suas necessidades. O Programa Luz para Todos atinge um fim específico dentro de um universo de ações que são de responsabilidade do Estado. Mas é preciso ter em mente que os interesses da população sempre aparecerão como objetivo final das ações, não na intenção de que o acesso de determinados serviços melhore a vida dessas pessoas, mas assim como afirma Foucault (2006, p.289)“ [...] melhorar a sorte da população [...]”.

A arte de governar, na perspectiva de Foucault (2006), deve criar uma continuidade entre as ações e formas de governamento (de si mesmo, da família, da empresa, da população, do Estado...), o que não deixa de ser uma forma de vigilância e controle das ações do Estado. O Ministério de Minas e Energia, na criação e execução do Programa Luz para Todos, possui esse controle das áreas de atuação mais urgente, devido aos baixos índices de acesso nos municípios a energia elétrica, nas comunidades atingidas por barragens, nos assentamentos, reservas extrativistas, terras indígenas, áreas quilombolas, escolas públicas rurais e etc.., fato que revela a vigilância do Estado pelas 
questões mais necessárias à população, mesmo que em alguns casos não as realize na prática.

\section{Análise de uma política pública: o programa "Luz para Todos"}

Podemos compreender que as políticas públicas têm por pressuposto uma orientação para as decisões da esfera pública em vista de manter o equilíbrio social, objetivando a mudança de realidades que necessitam de intervenções. Este processo de constituição de uma política pública está permeado por diversas finalidades e interesses das pessoas e grupos que estão envolvidos no processo. Uma política pública compreende, num primeiro momento, identificar qual o problema a ser tratado e na posterior elaboração de uma política para mitigar esse problema.

De acordo com Capella (2007), portanto, essa política deverá estar centrada numa realidade que apresenta a discrepância entre uma situação vigente em comparação com uma situação ideal em relação a um problema identificado, que consequentemente resultaria na intervenção pública. Na elaboração do programa "Luz para Todos" se observa uma referência concreta de que, através das constatações apresentadas pelo Censo de 2000, de que milhões de famílias no país ainda não tinham acesso à luz elétrica, uma intervenção da esfera pública se tornou necessária, a fim de que uma situação precária atual se tornasse mais próxima do ideal. Entretanto, no processo de identificação do problema algumas questões também surgiram em, como por exemplo, o questionamento se o governo deveria se envolver com este problema, e outra questão seria a maneira de como agir e se haveria mobilização suficiente a fim de que se inclua determinado problema na agenda decisória.

Outro ponto importante destacado por Capella (2007) trata-se da formação da agenda de decisões. Neste momento, identifica-se um espaço em que as questões problemáticas encontradas tenham a capacidade de se enquadrar dentro de um quadro de intervenção governamental. A partir de então, é importante ressaltar que se considera a ação como relevante, o que significa ao Estado tomar sua decisão em relação à ação. Quando analisamos o processo de formulação da política, o que se percebe é a concentração de esforços para definir entre as alternativas disponíveis para se estabelecer uma solução ao problema em questão. Este é o momento de tomar a dimensão dos problemas, suas possíveis consequências e sua adequação às limitações dos custos. As 
alternativas são colocadas em jogo como escolha da melhor que possa se adequar à necessidade da população e se alcançar os melhores resultados possíveis.

Contudo, conforme analisa Souza (2006, p.25), “o processo de formulação de políticas públicas constitui-se no estágio em que governos traduzem seus propósitos e plataformas eleitorais em programas e ações, que produzirão resultados ou mudanças no mundo real, delineando sua área e temática de atuação muito em relação aos seus interesses". Nessa perspectiva, podemos entender que a expansão da energia elétrica para as áreas rurais tem se transformado, ao longo da história moderna, num grande desafio para governos e formuladores de políticas públicas no Brasil. Enquanto de um lado percebemos que o país dificilmente chegará a um desenvolvimento econômico e social sem que se tenha acesso ao uso da eletricidade, do outro lado, o alto custo da prestação destes serviços ao meio rural tem significado um sério impedimento à sua expansão.

Entretanto, a partir de 2002, após um longo percurso de tentativas e se universalizar esse serviço público, que nem sempre deram certas, o país se viu diante da possibilidade de transformar essa situação desfavorável em uma nova realidade. Foi o momento esperado por parte das cinco grandes regiões brasileiras em vislumbrar o acesso ao serviço de eletrificação, principalmente nas regiões Norte e Nordeste, onde o índice de famílias sem energia elétrica era maior. Nos termos de Bittencourt (2008, p.16) podemos observar que "As condições econômicas relativamente favoráveis verificadas nos últimos anos podem ser apontadas como a razão que levou o Brasil a enfrentar o problema de forma mais decidida".

Tendo como prerrogativa o momento favorável do país em relação a sua atuação através das políticas públicas, o programa "Luz para Todos" buscaria fomentar a integração com outras ações ministeriais, envolvendo seus participantes em uma possível construção de uma configuração intersetorial das políticas públicas, incorporando-as em seu projeto político. Para o estabelecimento das premissas de implantação do programa, o governo federal, e os agentes executores assinaram um termo de compromisso, com a interveniência da Agência Nacional de Energia Elétrica (ANEEL) e da Eletrobrás, no qual ficaram definidas as metas anuais de atendimento no meio rural e os percentuais de participação financeira de cada uma das fontes de recursos que compõem o programa (MME, 2015).

De acordo com o seu manual de operacionalização, o programa "Luz para Todos" deveria também buscar uma integração aos diversos programas sociais e de 
desenvolvimento rural implementados pelo governo federal e pelos estados, de modo a se configurar um determinado arranjo entre as estruturas estatais envolvidas. Essa junção objetivou assegurar que o processo eletrificação do campo resultasse num desenvolvimento da produção agrícola do país, de modo a proporcionar um crescimento pela demanda de energia, o aumento da renda dos beneficiários e sua inclusão social. Porém, a história nos revela que a inclusão social até então não servia como um motivo relevante para o acesso à eletrificação no país.

Também é possível constatar que, no início de 2003, ainda se encontrava bastante indefinida a política governamental de universalização que acompanharia todo o processo, principalmente quando se envolvia a questão de alocação de recursos de fundos setoriais. Inicialmente, somente com as definições sobre o programa de universalização adotado pelo governo federal, se tornou possível a destinação desses fundos, bem como a distribuição dos recursos para as diferentes necessidades regionais.

Através da criação do programa "Luz para Todos", tendo em vista que já se tinha definido as suas principais fontes de recursos, tornou-se imprescindível delinear as regras de sua efetivação e as atribuições que seriam conferidas a cada um dos agentes, assim como quantificar as metas físicas a serem alcançadas por cada agente executor. Com isso, o manual de operacionalização do programa tem por finalidade definir a estrutura operacional a ser criada, assim como estabelecer os procedimentos e os critérios técnicos, financeiros e de prioridades a serem aplicados em sua execução.

Quando nos atemos ao processo de efetivação das políticas públicas observamos um conjunto de ações governamentais que possuem a finalidade de concretizar os objetivos que foram definidos. Durante a execução de uma política pública, algumas situações são muito importantes para o sucesso da ação, como por exemplo: a existência de um contexto político e econômico favorável; a disponibilidade de recursos e outros instrumentos necessários; decisão e iniciativa do governo em fazer valer o processo da formulação, de acordo com os termos de seus formuladores; um suporte político organizado dos grupos sociais afetados positivamente pela política e outros. Portanto, o processo de implementação baseia-se num equilíbrio entre o desenho institucional proposto pela formulação e sua execução junto à sociedade.

Em seu estudo, Menicucci (2007) aponta para o problema de uma visão clássica de que a efetivação de uma política pública seria apenas uma etapa do ciclo de formação, 
ao invés de se compreender que sua constituição estaria atrelada a uma interação entre os processos de formulação, implementação e avaliação da política pública.

Sobre esta questão aponta-se para dois aspectos relevantes na realização do programa. O primeiro apresenta um viés organizacional, que se refere a uma definição precisa da estrutura operacional e da função de cada agente a ser envolvido no processo, que geralmente são traduzidos na descrição de atribuições e de relacionamentos. Já o segundo aspecto é de natureza executiva, e compreendem as metas, as condições técnicas exigidas, os meios de acesso aos recursos e os demais procedimentos operacionais necessários a execução das atividades. Observando estes dois aspectos imagina-se ter importantes instrumentos de orientação para uma possível avaliação da implementação do programa.

\section{Considerações finais}

Considerando-se os propósitos e as dimensões do programa "Luz para Todos", não parece ficar dúvidas quanto à sua importância como política pública de inclusão social. Entretanto, a grande maioria das políticas públicas apresentadas no Brasil tem destacado mais o processo de formulação e elaboração de programas e projetos, ao passo que negligencia outras etapas que não podem ser consideradas irrelevantes ao ciclo da política, como o acompanhamento e a avaliação dos processos, dos resultados e impactos gerados por essas políticas.

É muito fácil perceber a escassez de estudos que contemplem estas etapas do processo que compreendem as políticas públicas. Essa constatação aponta como resultado problemas para os formuladores de políticas, assim como para a sociedade como um todo, tendo em vista que a falta de conhecimento sobre os resultados alcançados pelas políticas implementadas prejudica na hora da tomada de importantes decisões, seja na correção das eventuais falhas, ou mesmo na hora de continuar a execução da política. Outro fato que acaba se ocultando com a falta do acompanhamento e avaliação da política aplicada se trata da clareza a efetividade da aplicação dos recursos públicos.

É fundamental destacar é que apesar de ser um consenso que a disponibilidade de energia elétrica contribui significativamente para o desenvolvimento social e econômico da população brasileira, sobretudo aquelas que se encontram em espaços isolados como no caso de moradores de reservas extrativistas ou terras indígenas. No entanto, vários 
estudos mostram que somente o acesso ao serviço não é suficiente. O processo de expansão da eletrificação deveria estar atrelado à outras iniciativas e ações que se relacionassem com os setores da saúde, educação e produção, por exemplo. Nesse sentido, o acesso à energia elétrica significaria um agente facilitador de outras ações e medidas essenciais, de modo a favorecer o bem-estar da população.

É importante destacar que as ações do programa "Luz para Todos", deveriam surgir como resultado do envolvimento mais estrito entre agentes governamentais, que são dotados em tese de maior autonomia decisória, e que levasse em consideração as necessidades reais da população. Sendo assim, a busca por um desenvolvimento social e econômico rural apregoado pelo programa, deveria estar atrelado a uma inicial previsão das demandas reais, e a partir de então se formar uma conformação organizacional que orientasse o processo de inovações e mudanças, que pudessem estar articuladas à geração e melhoria de outros serviços básicos à população rural.

No entanto, muitas vezes não é o que se vê como características das políticas públicas no Brasil, que assumindo uma direção de universalização por parte de um Estado centralizador, as ações são executadas com caráter de urgência, em que os resultados devem ser quase que imediatos fatos que colaboram para imprecisões, devido à falta de planejamento.

\section{Referências}

BITTENCOURT, Eugênio Braúna. Avaliação do processo de implementação do Programa Luz para Todos no Estado do Ceará - Dissertação de mestrado apresentada à Universidade Federal do Ceará. 2010. $146 f$.

BRASIL. Decreto no 4.873, de 11 de novembro de 2003. Institui o Programa Nacional de Universalização do Acesso e Uso da Energia Elétrica - Luz para Todos e das outras providencias. Diário Oficial [da] República Federativa do Brasil, Brasília DF, 12 nov. 2003.

Ministério de Minas e Energia (MME). Portaria no 85, de 20 de fevereiro de 2009. Aprova a Revisão no 6 do Manual de Operacionalização que estabelece os critérios técnicos, financeiros, procedimentos e prioridades que serão aplicados no Programa Nacional de Universalização do Acesso e Uso da Energia Elétrica - Luz para Todos, na forma do Anexo divulgado na página do Ministério de Minas e Energia. Diário Oficial da União (DOU) de 25 de fevereiro de 2009.

BOURDIEU, Pierre. Razões práticas - sobre a teoria da ação. $6^{\mathrm{a}}$ ed. Tradução Mariza Corrêa. Campinas: Papirus, 2005. 224p. Cap. 4 "Espíritos de Estado: gênese e estrutura do campo burocrático", p. 91-135. 
CAPELLA, Ana C. N. "Perspectivas teóricas sobre o processo de formulação de políticas públicas". In: HOCHMAN, Gilberto et al. (Orgs.). Políticas públicas no Brasil. Rio de Janeiro: Editora Fiocruz, 2007. 398p. P. 87-122.

CARNOY, Martin. Estado e teoria política. $2^{a}$ ed. Tradução Instituto de Letras da PUC-Campinas. São Paulo: Papirus, 1988. Cap. 1 - "O Estado e o pensamento político norte-americano", pp. 1961.

FOUCAULT, Michel. Microfísica do poder. 22a ed. Rio de Janeiro: Edições Graal, 2006. Cap.XVII: “A governamentalidade”, p. 277- 293.

GIDDENS, Anthony. O Estado-nação e a violência: segundo volume de uma crítica contemporânea ao materialismo histórico. Tradução Beatriz Guimarães. São Paulo: Editora da Universidade de São Paulo, 2001. Cap. 1: "Estado, sociedade e história moderna", p. 33-59.

MELUCCI, Alberto. Por uma sociologia reflexiva - Pesquisa qualitativa e cultura. Petrópolis: Vozes, 2005, p.265-288.

MENICUCCI, Telma. "A implementação da reforma sanitária: a formação de uma política pública”. In: HOCHMAN, Gilberto et al. (Orgs.). Políticas públicas no Brasil. Rio de Janeiro: Editora Fiocruz, 2007. 398p. P. 87-122.

MINISTÉRIO DE MINAS E ENERGIA (MME). Manual do Operacionalização LPT 2015-2018. Disponível em: https://www.mme.gov.br/luzparatodos/downloads/manual_de_mperacionalizacao_do_programa _luz_para_todos_2015_2018.pdf Acesso em dezembro de 2016.

$\begin{array}{lllll}\text {.PPograma Luz para Todos. Disponível em } & \end{array}$
https://www.mme.gov.br/luzparatodos/Asp/o_programa.asp Acesso em abril de 2017.

SOUZA, Celina. "Políticas Públicas: uma revisão da literatura". Sociologias, Porto Alegre, ano $8, n^{\circ} 16$, jul/dez 2006, p. 20-45.

SOUZA, Celina. "Estado do campo da pesquisa em políticas públicas no Brasil”. In: HOCHMAN, Gilberto et al. (Orgs.). Políticas públicas no Brasil. Rio de Janeiro: Editora Fiocruz, 2007. 398p. Pp. 65-86. 